\title{
Mathematical Modeling and Numerical Simulation of the Buckling Stability Be- havior of Hybrid Beam
}

\author{
Abdelmalek Khebli (0000-0003-0825-3283)1, Salah Aguib (0000-0003-3314-3713) ${ }^{2}$, Chikh Noureddine (0000- \\ 0002-0825-9215)2, Kobzili Lallia (0000-0001-7571-222X)2,3, Meloussi Mounir (0000-0002-7170-7965)2,4 \\ ${ }^{1}$ Laboratoire Electrification des Entreprises Industrielles, Université de Boumerdès Algérie. E-mail: \\ a.khebli@univ-boumerdes.dz \\ ${ }^{2}$ Dynamic Motors and Vibroacoustic Laboratory, Faculty of Technology, University of Boumerdes35000, Algeria. \\ E-mail: 1.kobzili@univ-boumerdes.dz,_ s.aguib@univ-boumerdes.dz, chik_nour@yahoo.fr, \\ mounir.meloussi@gmail.com \\ ${ }^{3}$ Mechanical Engineering and Development Laboratory, National Polytechnic School, Alger, Algeria. E-mail: lal- \\ lia.kobzili@g.enp.edu.dz \\ ${ }^{4}$ CNRS UMR 7010, Institute of Physics of Nice, University Côte d'Azur, Parc Valrose 06108 Nice, France.
}

In this article, we studied the phenomenon of instability which is the buckling of the beam elaborated of steel (E36-S355), and magnetorheological elastomer subject to compression-flexion solicitation. The study of the influence of the intensity of the magnetic field on the buckling instability of compressed hybrid beams is done by a mathematical development using the Ritz approach and by a numerical simulation under the Abaqus calculation code. The obtained results show clearly that we can control the instabilities of the adaptive intelligent beams behavior by the magnetic field.

Keywords: Composite hybrid beam, Ritz approach modeling, Numerical simulation, Buckling stability

\section{Introduction}

Microcomposite magnetorheological elastomers (MMRE) belong to the family of intelligent composite materials, their rheological properties can be effectively controlled in near real time in a continuous manner and reversible by the application of an external magnetic field.

The buckling of structures is a subject which has been dealt with in numerous works, and which remains to this day a major problem in several sectors. Many of the solutions that can be found in literature, among these works we find the work carried out by Soomin Choi et al. [1], in this work the authors proposed a new higher-order beam bending theory that not only includes as many bending-related sectional modes as desired, but also provides the desired explicit stress-generalized force relations. To validate this latter theory, they calculated the static, free vibration, and buckling responses of several thinwalled rectangular hollow section beams. Qiduo Jin et al. [2] numerically analyzed the non-linear bending and the forced vibrations of the FG-GRC sandwich beams. The results obtained describe the static and dynamic behaviors as well as the optimal type of graphene reinforcement of these beams under different core-face sheet thickness ratios. Masoud Derakhshani et al. [3] made an analytical and experimental study of an energy recovery system based on bistable and deformable beams and a flexible piezoelectric made in PVDF. They found a good agreement between the results of the two studies. The work of Haning Xiu et al. [4] is devoted to study the linearized vibrational properties of pre-buckled beams along their stable transition paths. Numerical results are calculated using an elastic model and validated by a series of experiments. Ngoc Hieu Pham et al. [5] studied the global buckling capacity of cold rolled beams made of aluminum alloy. They developed a finite element model using Abaqus software. The results found are validated by a series of twenty tests. In order to study the behavior of lateral torsional buckling of HSS beams, Xiao-Lei Yan et al. [6] carried out an experimental and numerical study. They established a nonlinear finite element model taking into account the initial geometric imperfection. Chenyu Liu et al. [7] proposed a new type of reduced beam section connection (BR-RBS). It includes a buckling restrained assembled outside the reduced section connection (RBS). The results show that the proposed connection can satisfy the requirements of current seismic codes. Yuanbin Wang et al. [8] studied the nonlinear transverse vibrations of a hyperelastic beam under harmonic axial loading in subcritical buckling regime. They found that the properties of the material can modify the vibratory behavior. Samir Emam et al. [9] have developed a general formulation of the nonlinear buckling of deformable extensible beams subjected to shear. They found exact results which show that buckling load can be improved by 
designing materials from artificial metamaterials with a negative effective Poisson's ratio. Jen-San Chen et al. [10] studied the contact between two plane buckling beams pushed towards each other transversely. They adopted the vibration method to determine the stability of deformations. From this study, it is concluded that the equilibrium is stable when one of the squares of the eigenfrequencies is negative. Jiři Matlák et al. [11] have used of the high-energy electron beam source enables repeated surface quenching of chosen areas of an engineering part surface ; have shown that hardness values continuously decrease from the surface to the core of the material. Zongxing Zhang et al. [12] investigated the bending buckling behavior of hot-rolled $\mathrm{H}$-section beams made of Q345B steel corroded under four-point bending with various degrees of corrosion. The results show that the degree of corrosion influences the yield load, buckling load and ultimate load. R.M. Abo-bakr et al. [13] studied the buckling of a functionally graded (FG) beam under variable axial load by optimizing its power to obtain maximum load and minimum weight. The proposed model is efficient in the analysis, design and optimization of this beam. In order to analyze the free vibrations and buckling of bidirectional functionally graded sandwich beams, Cong Ich Le et al. [14] formulated a 3rd order shear strain beam member. They evaluated the natural frequencies and the buckling load using the formulated beam member. To solve the buckling problem of sandwich beams made of FG materials, Jun Liu et al. [15] proposed a new semi-analytical approach based on finite elements with stepped limits. The approach is validated by the existing solutions available in the literature, which confirms the accuracy and the adaptation of this method for these structures. In an effort to improve the critical buckling capacity of steel beams, Farid Abed et al. [16] made an experimental study and another numerical one using the finite elements and by the application of a pre-torsion. The initial preassembly shows a significant improvement in the buckling capacity of beams under fixed-end conditions rather than under pinned-end conditions. On the other hand, the length of the elements has no effect. Hadi Arvin et al. [17] presented in their work a comprehensive review to study the treatment of free vibrations of functionally graded (FG) rotating beams before and after buckling. The results show that the natural frequency of the pre-buckling decreases by increasing the volume fraction of the metallic phase and the speed of rotation of the SC beams. Mohammad Arefi et al. [18] numerically analyzed by Ritz method, the buckling and the free vibrations of the sandwich beams of a flexible core reinforced by nano-plates in functionally graded graphene. They determined the maximum and minimum natural frequencies as well as the critical buckling loads of the sandwich beam for the FG-X and FG-O distributions, respectively. Yoshihiro Kimura et al. [19] studied the elastic buckling resistance of I-cantilever beam. To perform this study, they proposed a new approximation method for plates with flexible boundary conditions. Linh T. M. phi et al. [20] studied the buckling and lateral buckling of a thin-walled mono-symmetric FG I-beam under uniformly distributed load and pure bending with different types of material distributions. They developed the dominant buckling equation and a finite element method. The results are validated by comparison with those in the literature. Haning Xiu et al. [21] studied the stabilization of higher order equilibria of prebuckled beams using piezoelectric actuation. Using a numerical modeling approach validated by experiments, they showed that third and fourth order stabilization is physically achievable on certain regions of the space parameters. In this work, Dita Jiroutova e [22] made a comparison between an experimental study of the deflection composite sandwich beam with theoretical models.. Wenzhong Yan et al. [23] presented analytical modeling to determine the influence of design parameters on the latching characteristics of bistable buckling beams subjected to a transverse point force. This model is checked against the results of a finite element model. Farzad Ebrahimi et al. [24] analyzed the buckling of a nanocomposite shell reinforced with graphene oxide powder (GOPR). They also presented results for the critical buckling load of these shells. They found that the Winkler and Pasernak coefficients have sufficient potential to increase critical buckling loads. A. Aguero et al. [25] presented a method which allows to calculate the amplitude of the initial imperfection for the lateral torsional buckling of beams with doubly symmetrical section.

According to the work done before, the buckling of MRE beams has not been treated, for that we are motivated by the analysis of the buckling of hybrid beams in magnetorheological elastomer which has been treated in this article. The beam is elaborated of three layers, an MRE core with varying properties under the application of the magnetic field and two steel skins. Two numerical methods were used to evaluate the behavior in buckling of the beam and to validate the results obtained, namely the Ritz method and finite element method under the Abaqus calculation code. The results obtained show the effectiveness of using this type of structures to remedy the effect of buckling.

\section{Mathematical modeling}

\subsection{Geometric modeling}

In our case, the geometric parameters of the beam are described in Figure 1. To simplify the modeling, 
the sandwich beam will be subjected to a buckling solicitation (flexion-compression).

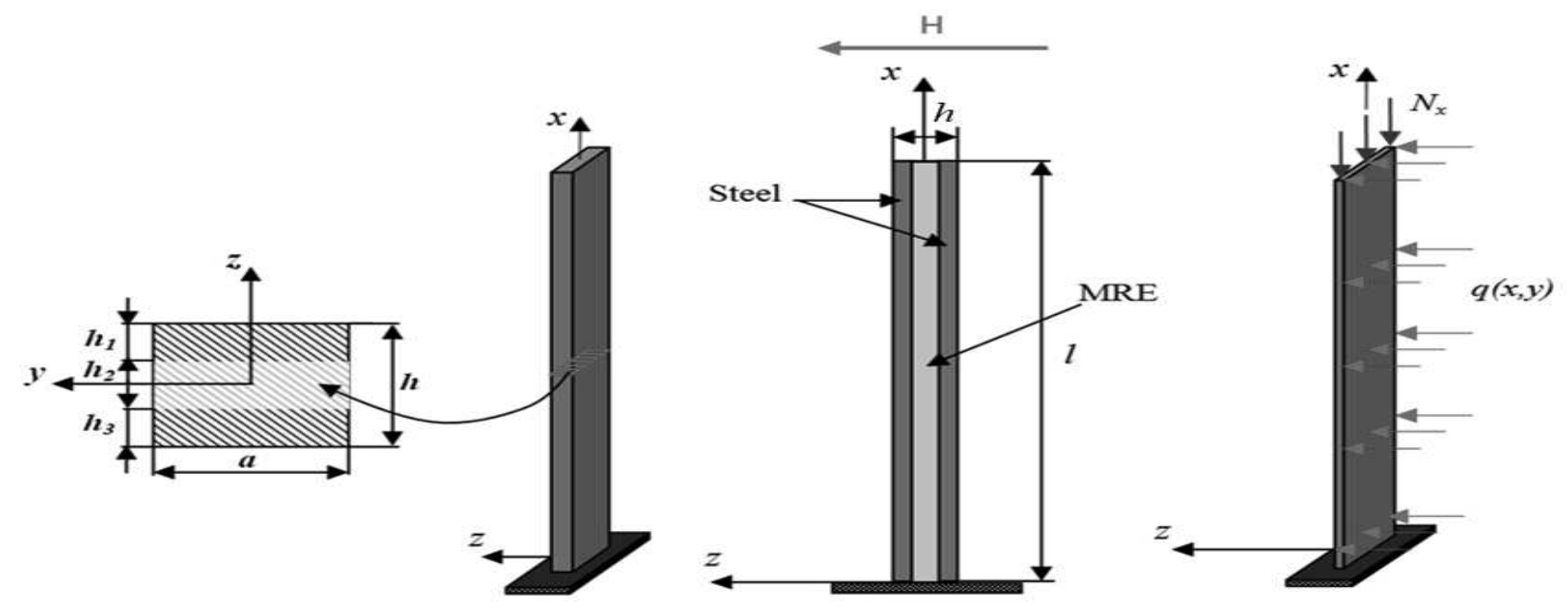

Fig. 1 Illustration and geometry modeling of the proposed sandwich beam.

\subsection{Displacement, stress and strain}

Consider the uniformly loaded beam for which the plane $x y$ coincides with the mean plane and therefore the ordinate $z$ is equal to zero. The components of displacement at a point, along the directions $x, y$ and $Z$, are denoted $u$ and $w$, respectively. When a lateral load causes deformation of the beam, the median surface at a point $\left(x_{(a / 2)}, y_{(a / 2)}\right)$, moves by $w$, the displacement field of the sandwich structure is identified as follows:

$$
\begin{gathered}
u^{i}(x, y, z, t)=u_{0}^{i}(x, y, t)-z_{i} w_{, x}^{i}(x, y, t) \\
w^{i}(x, y, z, t)=w_{0}^{i}(x, y, t)
\end{gathered}
$$

where $i=1,3$ references the top and bottom layers, respectively, and $z_{i}$ is the transverse coordinate in the local coordinate system of each layer. $u_{0}^{i}(x, y, t)$ and $w_{0}^{i}(x, y, t)$ are the displacements of the median planes while $u^{i}(x, y, z, t)$ and $w^{i}(x, y, z, t)$ denote the displacements of an arbitrary point along the axes $x$ and $z$ respectively. The

$$
\begin{gathered}
u^{2}(x, y, z, t)=\frac{u_{0}^{1}+u_{0}^{3}}{2}+\frac{1}{4}\left(h_{1} w_{, x}^{1}-h_{3} w_{, x}^{3}\right)+z_{2}\left(\frac{u_{0}^{1}-u_{0}^{3}}{h_{2}}+\frac{h_{1}}{2 h_{2}} w_{, x}^{1}+\frac{h_{3}}{2 h_{2}} w_{, x}^{3}\right) \\
w^{2}(x, y, z, t)=\frac{w^{1}+w^{3}}{2}+z_{2} \frac{w^{1}-w^{3}}{h_{2}}
\end{gathered}
$$

using the Von-Karman formulation, the nonlinear strain-displacement relationships, the normal and inplane shear strain components of the face layers can be expressed as follows:

$$
\begin{aligned}
\left\{\varepsilon^{i}\right\}=\left(\begin{array}{c}
\varepsilon_{x}^{i} \\
\varepsilon_{y}^{i} \\
\gamma_{x y}^{i}
\end{array}\right), i=1,3 \quad \text { (4) } \begin{array}{l}
\text { and after strain from which } \\
\text { components of the middle lay } \\
\text { zand } y-z \text { can be introduced as }
\end{array} \\
\gamma_{x z}^{2}=u_{, z}^{2}+w_{, x}^{2}=\frac{u_{0}^{1}-u_{0}^{3}}{h_{2}}+\left(\frac{h_{1}+h_{2}+2 z_{2}}{2 h_{2}}\right) w_{, x}^{1}+\left(\frac{h_{3}+h_{2}-2 z_{2}}{2 h_{2}}\right) w_{, x}^{3} \\
\gamma_{y z}^{2}=v_{, z}^{2}+w_{, y}^{2}=\frac{v_{0}^{1}-v_{0}^{3}}{h_{2}}+\left(\frac{h_{1}+h_{2}+2 z_{2}}{2 h_{2}}\right) w_{, y}^{1}+\left(\frac{h_{3}+h_{2}-2 z_{2}}{2 h_{2}}\right) w_{, y}^{3}(6)
\end{aligned}
$$

where $\varepsilon_{x}^{i}$ and $\varepsilon_{y}^{i}$ are the normal strain components along the axes $x$ and $y$, respectively, and $\gamma_{x y}^{i}$ is the shear strain in the ith layer.

Figure 2 shows the MRE sandwich beam before and after strain from which the shear strain components of the middle layer in the planes $x-$ $z$ and $y-z$ can be introduced as follows: 


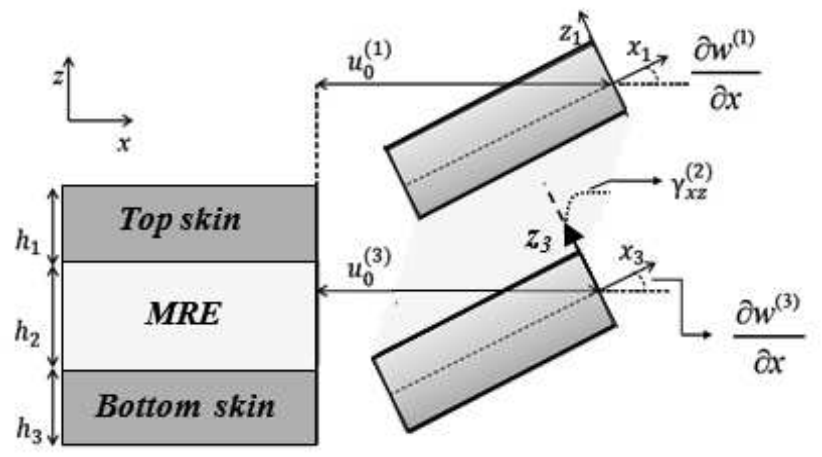

a)

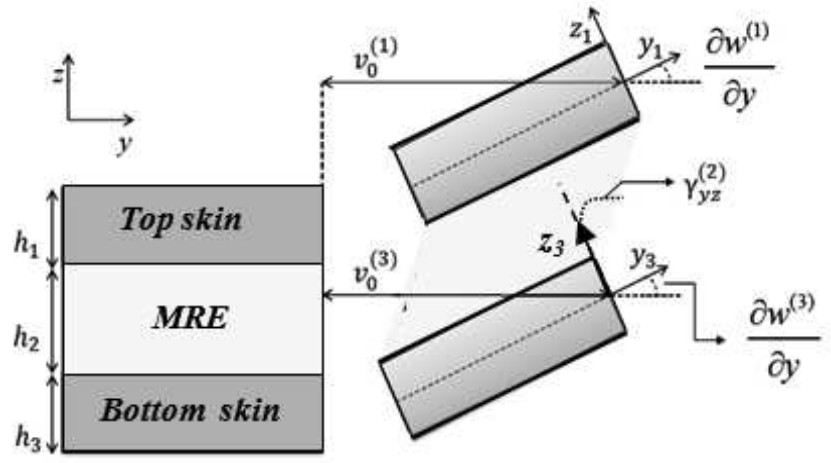

b)

Fig. 2 Sandwich beam in MRE not deformed and deformed in the planes, a) $x$-z and b) $y$-z:

Assuming a weak strain condition (small strain), Hooke's law can be used to obtain the normal stress

$$
\begin{gathered}
\left(\begin{array}{c}
\sigma_{x}^{i} \\
\sigma_{y}^{i} \\
\tau_{x y}^{i}
\end{array}\right)=\frac{E_{i}}{\left(1-v_{i}^{2}\right)}\left[\begin{array}{cc}
1 & v_{i} \\
v_{i} & 1 \\
0 & 0
\end{array}\right. \\
\tau_{x z}^{2}=G^{*} \gamma_{x z}^{2} \\
\tau_{y z}^{2}=G^{*} \gamma_{y z}^{2}
\end{gathered}
$$

where $\sigma$ and $\tau$ are the components of the normal and shear stress, $E$ and $v$ are the Young's modulus and the Poisson's ratio of the face layers. $G^{*}=G^{\prime}+i G^{\prime \prime}$ is the complex shear modulus of the MRE layer, where, $G^{\prime}$ is the storage modulus and, $G^{\prime \prime}$ the dissipation modulus depending on the applied magnetic field, the amplitude of the shear strain undergone by the MRE core and the excitation frequency.

\subsection{Solving the buckling problem by the Ritz method}

The exact solutions of the buckling problem are obtained only for beams in conventional materials, and with simple boundary conditions. In practice, however, many cases are encountered in which exact and shear components in the sandwich beam structure as follows:

$$
\left.\begin{array}{c}
0 \\
0 \\
\left(1-v_{i}\right) / 2
\end{array}\right]\left(\begin{array}{c}
\varepsilon_{x}^{i} \\
\varepsilon_{y}^{i} \\
\gamma_{x y}^{i}
\end{array}\right) i=1,3
$$

solutions are not available and approximate methods must be utilized. In this work, we consider an intelligent beam elaborated of magnetorheological elastomer subjected to a transverse load $q(x, y)$ and a compressive force $N_{x}$ (see Figure 1), we are looking for approximate solutions in using the Ritz method. This approach is equally applicable to buckling problem. Each of these problem is governed by an energy condition which can be written in the following form:

$$
\frac{\partial U}{\partial A}=\text { Stationary value }
$$

\section{Energy formulation}

The strain energy of the top and bottom layers of the MRE composite sandwich beam can be expressed as follows:

$$
\begin{aligned}
& U_{1}=\int_{0}^{l} \int_{0}^{a}\left\{D_{111}\left(\frac{\partial^{2} w_{1}}{\partial x^{2}}\right)^{2}+2 D_{112}\left(\frac{\partial^{2} w_{1}}{\partial x^{2}} \frac{\partial^{2} w_{1}}{\partial y^{2}}\right)+D_{122}\left(\frac{\partial^{2} w_{1}}{\partial y^{2}}\right)^{2}+4 D_{166}\left(\frac{\partial^{2} w_{1}}{\partial x \partial y}\right)^{2}+N_{x}\left(\frac{\partial^{2} w_{1}}{\partial x^{2}}\right)^{2}\right\} d x d y \\
& U_{3}=\int_{0}^{l} \int_{0}^{a}\left\{D_{311}\left(\frac{\partial^{2} w_{3}}{\partial x^{2}}\right)^{2}+2 D_{312}\left(\frac{\partial^{2} w_{3}}{\partial x^{2}} \frac{\partial^{2} w_{3}}{\partial y^{2}}\right)+D_{322}\left(\frac{\partial^{2} w_{3}}{\partial y^{2}}\right)^{2}+4 D_{366}\left(\frac{\partial^{2} w_{3}}{\partial x \partial y}\right)^{2}+N_{x}\left(\frac{\partial^{2} w_{1}}{\partial x^{2}}\right)^{2}\right\} d x d y
\end{aligned}
$$

The strain energy of the elastomeric core is given as follows:

$$
\begin{gathered}
U_{2}=\frac{2 d}{h_{2}} \int_{0}^{l} \int_{0}^{a}\left[G_{2}^{\prime}(1+i \eta)\left(\frac{\partial w}{\partial x}\right)^{2}+N_{x}\left(\frac{\partial^{2} w_{1}}{\partial x^{2}}\right)^{2}\right] d x d y \\
d=\frac{1}{2}\left(h_{1}+2 h_{2}+h_{3}\right)
\end{gathered}
$$

For isotropic materials, the bending rigidity is given as follows:

$$
D_{11}=D_{22}=D, \quad D_{12}=v D, D_{66}=\left(\frac{1-v}{2}\right) D
$$

wherewis the transverse displacement of the beam, $\mathrm{G}_{2}$ and $h_{2}$ are respectively the shear modulus and the thickness of the elastomer respectively.

The total strain energy of the sandwich beam $(U)$ can be expressed as follows

$$
X_{m}(x)=\cos \frac{\lambda_{m} x}{l}-\cosh \frac{\lambda_{m} x}{l}-\gamma_{m}\left(\sin \frac{\lambda_{m} x}{l}-\sinh \frac{\lambda_{m} x}{l}\right)
$$




$$
Y_{n}(y)=\cos \frac{\lambda_{n} y}{a}-\cosh \frac{\lambda_{n} y}{a}-\gamma_{n}\left(\sin \frac{\lambda_{n} y}{a}-\sinh \frac{\lambda_{n} y}{a}\right)
$$

The approximate solution is sought in the form of a double series with separate variables

$$
\begin{array}{r}
w=\sum_{m=1}^{M} \sum_{n=1}^{N} A_{m n} X_{m}(x) Y_{n}(y) \\
\frac{\partial U}{\partial A_{m n}}=q(x, y)
\end{array}
$$

The functions $X_{m}(x)$ and $Y_{n}(x)$ must constitute functional bases.

In the static case, equation (10) becomes:

$$
\text { for }\left\{\begin{array}{l}
m=1,2, \ldots \ldots M \\
n=1,2, \ldots \ldots . .
\end{array}\right.
$$

where $U$ is the strain energy. To find the approximate expressions, we derive each term from equations (11) (13) as follows:

From where

$$
\frac{\partial^{2} w}{\partial x^{2}}=\sum_{m=1}^{M} \sum_{n=1}^{N} A_{m n} \frac{d^{2} X_{m}}{d x^{2}} Y_{n}
$$

$$
\left(\frac{\partial^{2} w}{\partial x^{2}}\right)^{2}=\sum_{m=1}^{M} \sum_{n=1}^{N} \sum_{i=1}^{M} \sum_{j=1}^{N} A_{m n} A_{i j} \frac{d^{2} X_{m}}{d x^{2}} \frac{d^{2} X_{i}}{d x^{2}} Y_{n} Y_{j}
$$

The derivation of (22) with respect to $A_{m n}$ gives:

$$
\frac{1}{2} \frac{\partial}{\partial A_{m n}}\left(\frac{\partial^{2} w}{\partial x^{2}}\right)^{2}=\sum_{i=1}^{M} \sum_{j=1}^{N} A_{i j} \frac{d^{2} X_{m}}{d x^{2}} \frac{d^{2} X_{i}}{d x^{2}} Y_{n} Y_{j}
$$

The integration of this term is written as:

$$
\frac{1}{2} \frac{\partial}{\partial A_{m n}} \int_{0}^{l} \int_{0}^{a}\left(\frac{\partial^{2} w}{\partial x^{2}}\right)^{2}=\sum_{i=1}^{M} \sum_{j=1}^{N} A_{i j} \int_{0}^{l} \frac{d^{2} X_{m}}{d x^{2}} \frac{d^{2} X_{i}}{d x^{2}} d x \int_{0}^{a} Y_{n} Y_{i} d y
$$

By combining the equations (11) - (13), and transverse load, we obtain the following algebraic equations.

$$
\begin{gathered}
\sum_{i=1}^{M} \sum_{j=1}^{N}\left\{D \int_{0}^{l} \frac{d^{2} X_{i}}{d X^{2}} \frac{d^{2} X_{m}}{d X^{2}} d x \int_{0}^{a} Y_{j} Y_{n} d y+v D\left[\int_{0}^{l} X_{m} \frac{d^{2} X_{i}}{d X^{2}} d x \int_{0}^{a} Y_{j} \frac{d^{2} Y_{n}}{d Y} d Y+\int_{0}^{l} X i \frac{d^{2} X_{m}}{d X^{2}} d x \int_{0}^{a} Y_{n} \frac{d^{2} Y_{j}}{d Y^{2}} d Y\right]\right. \\
+D \int_{0}^{l} X_{i} X_{m} d x \int_{0}^{a} \frac{d^{2} Y_{j}}{d Y^{2}} \frac{d^{2} Y_{n}}{d Y^{2}} d y+4(1-v) D \int_{0}^{l} \frac{d X_{i}}{d X} \frac{d X_{m}}{d X} d x \int_{0}^{a} \frac{d Y_{j}}{d Y} \frac{d Y_{n}}{d Y} d y+D \int_{0}^{l} \frac{d^{2} X_{i}}{d X^{2}} \frac{d^{2} X_{m}}{d X^{2}} d x \int_{0}^{a} Y_{j} Y_{n} d y \\
+v D\left[\int_{0}^{l} X_{m} \frac{d^{2} X_{i}}{d X^{2}} d x \int_{0}^{a} Y_{j} \frac{d^{2} Y_{n}}{d Y^{2}} d y+\int_{0}^{l} X_{i} \frac{d^{2} X_{m}}{d X^{2}} d x \int_{0}^{a} Y_{n} \frac{d^{2} Y_{j}}{d Y^{2}} d y\right]+D \int_{0}^{l} X_{i} X_{m} d x \int_{0}^{a} \frac{d^{2} Y_{j}}{d Y^{2}} \frac{d^{2} Y_{n}}{d Y^{2}} d y \\
+4(1-v) D \int_{0}^{l} \frac{d X_{i}}{d X} \frac{d X_{m}}{d X} d x \int_{0}^{a} \frac{d Y_{j}}{d Y} \frac{d Y_{n}}{d Y} d y+\frac{2 d}{h_{2}} G_{c}(1+i \eta) \int_{0}^{l} \frac{d X_{i}}{d x} \frac{d X_{m}}{d X} d x \int_{0}^{a} \frac{d Y_{j}}{d Y} \frac{d Y_{n}}{d Y} d y \\
\left.+3 N_{x} \int_{0}^{l} \frac{d X_{i}}{d X} \frac{d X_{m}}{d X} d x \int_{0}^{a} Y_{j} Y_{n} d y\right\} A_{i j}=q \int_{0}^{l} X_{m} d x \int_{0}^{a} Y_{n} d y
\end{gathered}
$$

To express these integrals, it is convenient to introduce the reduced variables by setting:

The expression (24) is written:

$$
\begin{array}{lll}
\xi=\frac{x}{l} & (\text { for } \quad x=0 \Rightarrow \xi=0 & \text { and for } x=l \Rightarrow \xi=1) \\
\vartheta=\frac{y}{a} & (\text { for } \quad y=0 \Rightarrow \vartheta=0 & \text { and for } y=a \Rightarrow \vartheta=1)
\end{array}
$$

$$
\frac{1}{2} \frac{\partial}{\partial A_{m n}} \int_{0}^{l} \int_{0}^{a}\left(\frac{\partial^{2} w}{\partial x^{2}}\right)^{2}=\sum_{i=1}^{M} \sum_{j=1}^{N} A_{i j} \frac{a}{l^{3}} \int_{0}^{1} \frac{d^{2} X_{m}}{d \xi^{2}} \frac{d^{2} X_{i}}{d \xi^{2}} d \xi \int_{0}^{1} Y_{n} Y_{i} d \vartheta
$$

By replacing equations (28) in (25), we obtain the following algebraic equations.

$$
\begin{gathered}
\sum_{i=1}^{M} \sum_{j=1}^{N}\left\{\frac{a D}{l^{3}} \int_{0}^{1} \frac{d^{2} X_{i}}{d \zeta^{2}} \frac{d^{2} X_{m}}{d \zeta^{2}} d \zeta \int_{0}^{1} Y_{j} Y_{n} d \vartheta+v D\left[\frac{a}{l} \int_{0}^{1} X_{m} \frac{d^{2} X_{i}}{d \zeta^{2}} d \zeta \int_{0}^{1} Y_{j} \frac{d^{2} Y_{n}}{d \vartheta^{2}} d \vartheta+\right.\right. \\
\left.\frac{1}{l a} \int_{0}^{1} X i \frac{d^{2} X_{m}}{d \zeta^{2}} d \zeta \int_{0}^{1} Y_{n} \frac{d^{2} Y_{j}}{d \vartheta^{2}} d \vartheta\right]+\frac{l D}{a^{3}} \int_{0}^{1} X_{i} X_{m} d \zeta \int_{0}^{1} \frac{d^{2} Y_{j}}{d \vartheta^{2}} \frac{d^{2} Y_{n}}{d \vartheta^{2}} d \vartheta+\frac{4(1-v)}{2 l a} D \int_{0}^{1} \frac{d X_{i}}{d \zeta} \frac{d X_{m}}{d \zeta} d \zeta \int_{0}^{1} \frac{d Y_{j}}{d \vartheta} \frac{d Y_{n}}{d \vartheta} d \vartheta+ \\
\frac{a D}{l^{3}} \int_{0}^{1} \frac{d^{2} X_{i}}{d \zeta^{2}} \frac{d^{2} X_{m}}{d \zeta^{2}} d \zeta \int_{0}^{1} Y_{j} Y_{n} d \vartheta+v \frac{D}{l a}\left[\int_{0}^{1} X_{m} \frac{d^{2} X_{i}}{d \zeta^{2}} d \zeta \int_{0}^{1} Y_{j} \frac{d^{2} Y_{n}}{d \vartheta^{2}} d \vartheta+\int_{0}^{1} X i \frac{d^{2} X_{m}}{d \zeta^{2}} d \zeta \int_{0}^{1} Y_{n} \frac{d^{2} Y_{j}}{d \vartheta^{2}} d \vartheta\right]+ \\
\frac{l D}{a^{3}} \int_{0}^{1} X_{i} X_{m} d \zeta \int_{0}^{1} \frac{d^{2} Y_{j}}{d \vartheta^{2}} \frac{d^{2} Y_{n}}{d \vartheta^{2}} d \vartheta \\
+\frac{4(1-v)}{2 a l} D \int_{0}^{1} \frac{d X_{i}}{d \zeta} \frac{d X_{m}}{d \zeta} d \zeta \int_{0}^{1} \frac{d Y_{j}}{d \vartheta} \frac{d Y_{n}}{d \vartheta} d \vartheta+\frac{2 d}{h_{2} l a} G_{c}(1+i \eta) \int_{0}^{1} \frac{d X_{i}}{d \zeta} \frac{d X_{m}}{d \zeta} d \zeta \int_{0}^{1} \frac{d Y_{j}}{d \vartheta} \frac{d Y_{n}}{d \vartheta} d \vartheta \\
\left.+\frac{3 a}{l} N_{x} \int_{0}^{1} \frac{d X_{i}}{d \zeta} \frac{d X_{m}}{d \zeta} d \zeta \int_{0}^{1} Y_{j} Y_{n} d \vartheta\right\} A_{i j}=q a l \int_{0}^{1} X_{m} d \zeta \int_{0}^{1} Y_{n} d \vartheta
\end{gathered}
$$

with the dimensionless integrals (29) are expressed by the following reduced form:

$$
\begin{array}{lll}
I_{m i}^{p q}=\int_{0}^{1} \frac{d^{p} X_{m}}{d \xi^{p}} \frac{d^{q} Y_{i}}{d \xi^{q}} d \xi & m, i=1,2, \ldots, M & p q=00,02,11,20,22 . \\
J_{n j}^{r s}=\int_{0}^{1} \frac{d^{r} Y_{n}}{d \vartheta^{r}} \frac{d^{s} Y_{j}}{d \vartheta^{s}} d \vartheta & n, j=1,2, \ldots, N & r s=00,02,11,20,22 .
\end{array}
$$

these integrals $I_{m i}^{p q}$ and $I_{n j}^{r s}$ are calculated directly using the Maple software.
After substitution, equations (30) and (31) reduces as follows: 


$$
\begin{aligned}
& \sum_{i}^{M} \sum_{j}^{N}\left\{D_{11} I_{m i}^{22} J_{n j}^{00}+\left[D_{12}\left(I_{m i}^{20} J_{n j}^{02}+I_{m i}^{02} J_{n j}^{20}\right)+4 D_{66} I_{m i}^{11} J_{n j}^{11}\right]+D_{22} I_{m i}^{00} J_{n j}^{22}+\frac{a^{2} h_{2}^{3}}{24 G_{2}^{*}} I_{m i}^{11} J_{n j}^{00}+\frac{a^{2} h_{2}^{3}}{24 G_{2}^{*}} I_{m i}^{00} J_{n j}^{11}+\right. \\
& \left.a^{4}\left(I_{m i}^{00} J_{n j}^{00}+I_{m i}^{00} J_{n j}^{00}\right)+\frac{3 a}{l} N_{x} I_{i m}^{11} J_{j n}^{00}\right\} A_{i j}==q_{0} a^{4} I_{m}^{0} J_{n}^{0}
\end{aligned}
$$

The system of equations (32) is written in the following compact form:

$$
\sum_{i}^{M} \sum_{j}^{N} K_{i m j n} A_{i j}=0
$$

$$
K_{i m j n}=D_{11} I_{m i}^{22} J_{n j}^{00}+\left[D_{12}\left(I_{m i}^{20} J_{n j}^{02}+I_{m i}^{02} J_{n j}^{20}\right)+4 D_{66} I_{m i}^{11} J_{n j}^{11}\right]+D_{22} I_{m i}^{00} J_{n j}^{22}+\frac{a^{2} h_{2}^{3}}{24 G_{2}^{*}} I_{m i}^{11} J_{n j}^{00}+
$$

with :

$$
\frac{a^{2} h_{2}^{3}}{24 G_{2}^{*}} I_{m i}^{00} J_{n j}^{11}+a^{4}\left(I_{m i}^{00} J_{n j}^{00}+I_{m i}^{00} J_{n j}^{00}\right)+\frac{3 a}{l} N_{x} I_{i m}^{11} J_{j n}^{00}
$$

where, $K_{\text {imjn }}$ is the total rigidity matrix.

To obtain the displacements, we solve the following equation (35):

$$
\left[K_{i m j n}\right]\left\{U_{i j}\right\}=0
$$

The results obtained using equation (35) developed by the Ritz approach are compared with those obtained by the finite element method using the Abaqus software. The flowchart of the computation of displacements by the two methods, Ritz and FEM is given by Figure 3 .

In this section we will illustrate the results found by exploiting the mathematical model developed by the Ritz ap-proach (Section 2).

The average Young's modulus as a function of the magnetic field intensity of magnetorheological elastomer test samples charged with $30 \%$ of iron particles was determined experimentally using a viscoanalyzer (DMA 450+) from the laboratory of condensed matter physics in Nice, France, marketed by Metravib. The analysis results are given in Table 1 . The conservative $G$ ', dissipative $G^{\prime}$ 'and loss factor $\eta$ moduli are given by Nedjar et al $[26,27]$.

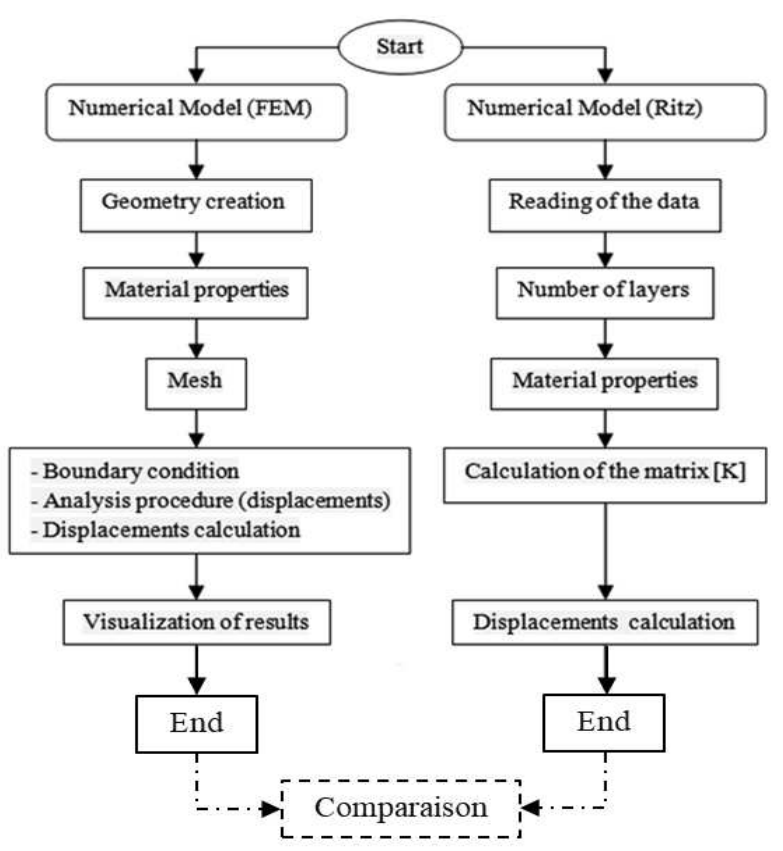

Fig. 3 Flowchart of displacement calculation. Ritr modeling results and discussions

Tab. 1 Mechanical and geometric properties of the MRE core

\begin{tabular}{c|c|c}
\hline \multicolumn{3}{|c}{ Mechanical properties } \\
\hline Young's modulus $(\mathrm{MPa})$ & Poisson coefficient $(\mathrm{v})$ & Mass density $\boldsymbol{\rho}(\mathrm{kg} / \mathrm{m} 3)$ \\
\hline 18.60 & 0.48 & 1100 \\
\hline \multicolumn{2}{c}{$\mathrm{L}(\mathrm{mm})$} \\
\hline $\mathrm{h}_{2}(\mathrm{~mm})$ & Geometric properties \\
\hline 2 & \multicolumn{2}{c}{1500} \\
\hline
\end{tabular}

Tab. 2Mechanical and geometric properties of the steel (E36 - S355)

\begin{tabular}{c|c|c}
\hline \multicolumn{3}{c}{ Mechanical properties } \\
\hline$\rho\left(\boldsymbol{k g} / \boldsymbol{m}^{\mathbf{3}}\right)$ & $E(\boldsymbol{M P a})$ & $\boldsymbol{v}$ \\
\hline 7800 & 210000 & 0.3 \\
\hline $\mathrm{L}(\mathrm{mm})$ & Geometric properties \\
\hline 1500 & $\mathrm{a}(\mathrm{mm})$ & $\mathrm{h}_{1,3}(\mathrm{~mm})$ \\
\hline
\end{tabular}

The mechanical and geometric characteristics of the part of the beam fabricated of steel are summarized in Table 2.

Figure 4 shows the results of comparison of the deformation calculated for an axial force in compression and in flexion. This figure shows the maximum deflection obtained when an axial force is applied to the end of a beam embedded at $\mathrm{x}=0$, and 
stressed by a load Nx at $\mathrm{x}=\mathrm{L}$. We can observe the instability which turns out as soon as the axial force in compression reaches $70 \%$ of its critical value, whereas on the contrary the deflection is stable for the case of axial tensile. To this end, in what follows we will deal with the case of compressive solicitation.

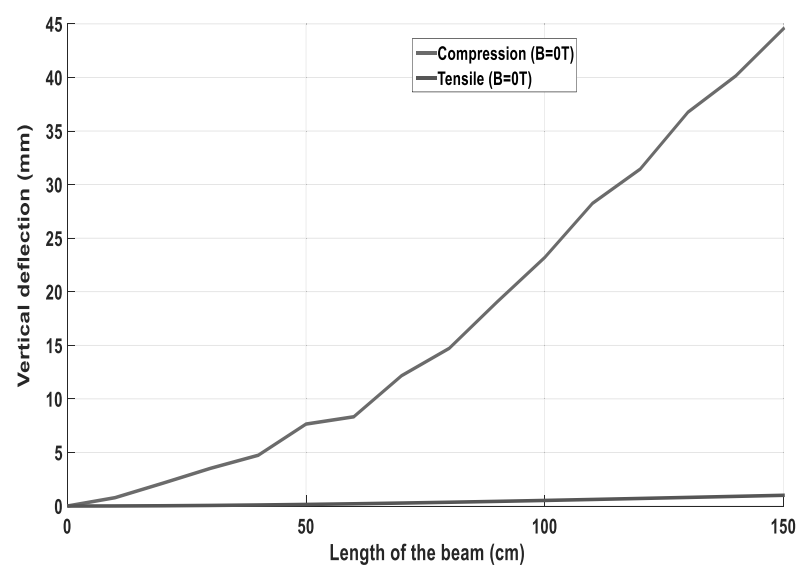

Fig. 4 Variation of vertical deflection as a function of length without magnetic field intensity.

The results of the deformation in the case of the zero magnetic field intensity are compared with those which have been found for a magnetic field intensity of $0,0.25,0.5$ and $1 T$. Figure 5 clearly shows the effect of the magnetic field on the buckling behavior of smart beams made in magnetorheological elastomer. It can be seen from Figure 5 that the beam is highly unstable for zero magnetic field intensity; on the other hand, this instability decreases with the increase in the magnetic field intensity. Note that the deflection is practically stable for magnetic field intensity equal to 1T. In conclusion, from this work, we show that the application of a magnetic field produces an apparent stiffening of the elastomer; this stiffening is responsible of the creation of the iron particles columns in the form of pseudo-fibers.

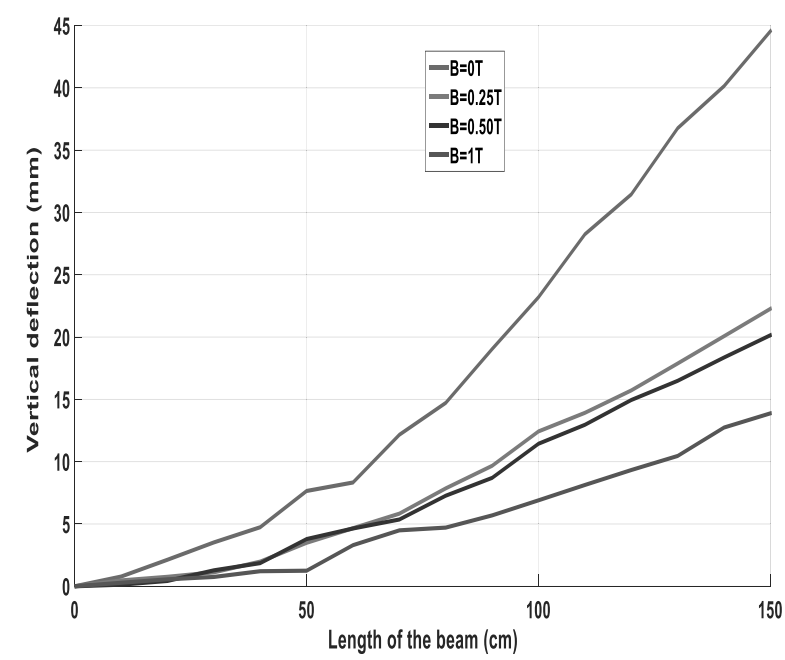

Fig. 5 Variation of the vertical deflection in compression as a function of the length with different magnetic field intensities.
This figure clearly highlights the influence of the magnetic field on the behavior of the beam. The bending stiffness is improved by the fact that the different intensities increase the tensile modulus. This allowed us to conclude that the increase in the magnetic field favorites the increase in the bending stiffness of the magnetorheological elastomer structure. The total charge without the effect of the magnetic field reaches a value of approximately $500 \mathrm{~N}$ which gives bending amplitude of $44.55 \mathrm{~mm}$, this charge reaches a value of approximately $250 \mathrm{~N}$ which gives bending amplitude of $13.92 \mathrm{~mm}$ for a magnetic field intensity of $1 \mathrm{~T}$, i.e. a reduction in the value of the bending amplitude of $150 \%$.

Figure 6 presents the Ritz approach results in term of evolution of the buckling force $\mathrm{Nx}$ submitted by the magnetorheological elastomer beam according to the vertical deformation. There are five curves depending on the variation of the intensity of the magnetic field (0T, $0.25 \mathrm{~T}, 0.5 \mathrm{~T}, 0.75 \mathrm{~T}$ and $1 \mathrm{~T}$ ). The vertical deformation decreases with the increase in the intensity of the magnetic field, i.e. it decreases with the increase in the magnetic force, the latter is considered a resistance force due to the increase rigidity of MRE under the effect of the magnetic field.

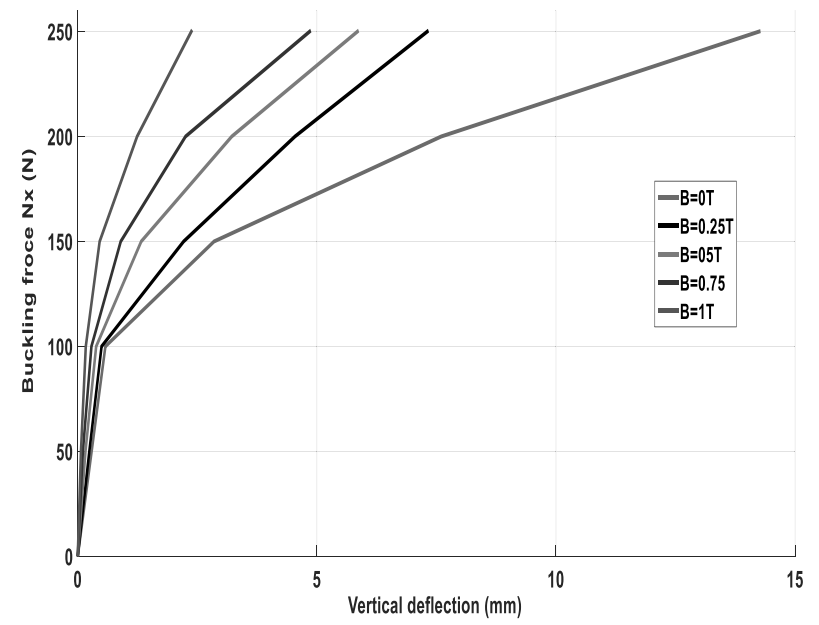

Fig. 6 Influence of the magnetic field on the deflection as a function of the buckling force submitted by the MRE beam.

We see a decrease a reduction of $50 \%$ of the vertical deformation for intensity of the magnetic field of $0.25 \mathrm{~T}$, and a reduction of $90 \%$ for a magnetic field intensity of $1 \mathrm{~T}$ compared to the vertical deformation without magnetic field.

\section{Numerical simulation}

After the study of the behavior in buckling by the Ritz approach method, we established a numerical simulation under Abaqus software for the study of the elastomer beams steel-magnetorheological compressed inflected. The objective of this study was 
to verify the results found by the semi-analytical method and to determine the influence of application of a magnetic field on the buckling behavior of the beams. To model the rheological behavior of the magnetorheological elastomer under Abaqus, we used the 8-branch Maxwell rheological model. Figure 7 shows the geometry, the boundary conditions, the loading and the mesh of the beam. To verify whether the discretization size is adequate for the buckling analysis, simulations were made under the same conditions. One will compare the displacements in buckling in the beam for various meshes, going from $0.1 \mathrm{~mm}$ to $1 \mathrm{~mm}$.
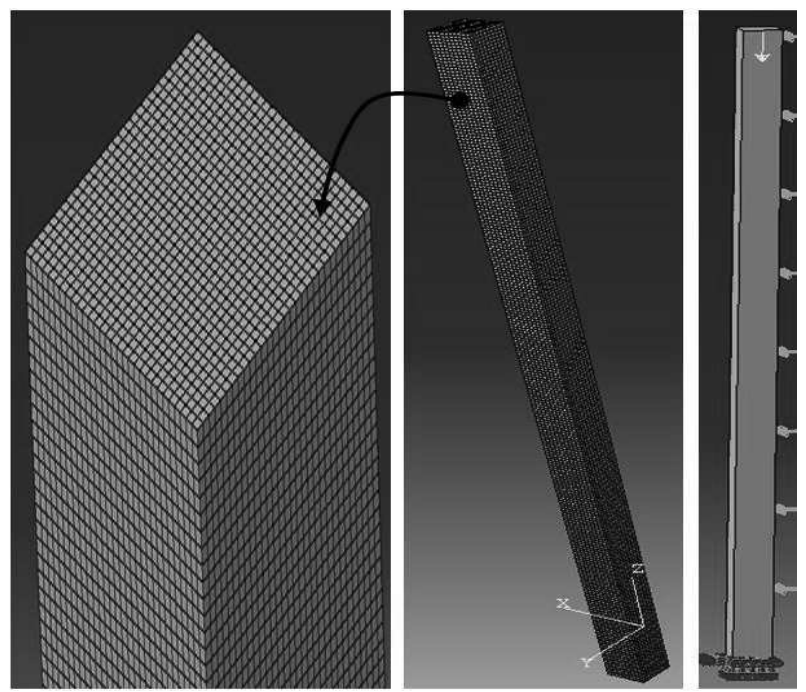

Fig. 7 Geometry, boundary conditions, loading and mesh of the beam.

The results of the simulations show that the displacements of the beam after buckling are practically the same for all the meshes of the size less than or equal to $0.4 \mathrm{~mm}$, (Figure 8), then the results are almost identical in terms of displacement.

It is thus judicious to choose a mesh whose length is lower or equal to $0.4 \mathrm{~mm}$ to carry out good results of buckling. This discretization seems to be a good compromise because choosing a mesh too fine would lead to longer computation times without much influence on the results. To this end, we have discretized the beam with a brick element with 8 nodes of size $0.2 \times 0.2 \times 0.2 \mathrm{~mm}$. The results of this discretization are represented in Figure 7.

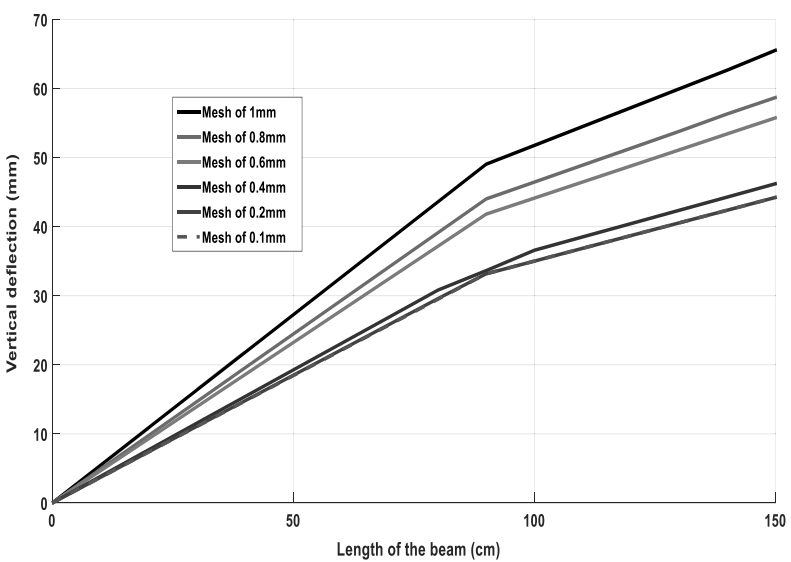

Fig. 8 Convergence and choice of the size of the beam mesh element.

The results of the numerical simulation by the finite element method under the Abaqus software with different magnetic field intensities are presented in Figure 9.

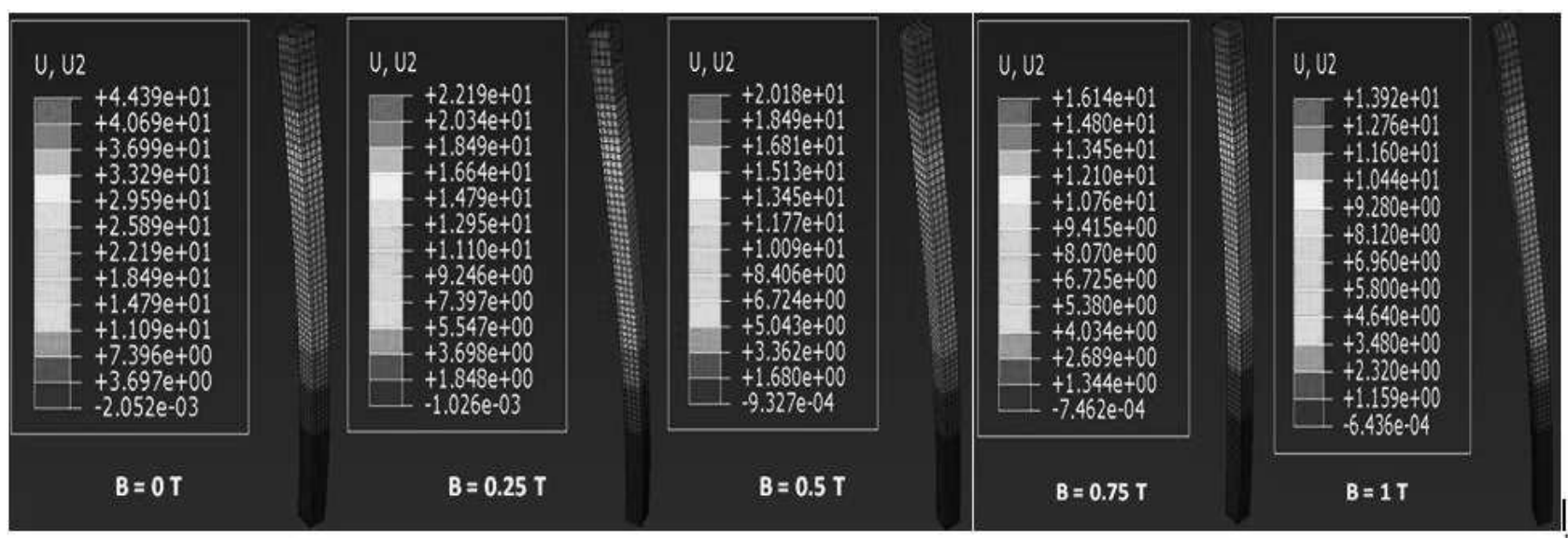

Fig. 9 Variation of the vertical deflection as a function of different magnetic field intensities.

\section{Comparison of results and discussion}

In this section, we compare the results obtained by Ritz approach method using Matlab code with those found by numerical simulation using Abaqus software.

In Figure 10, the instability of the magnetorheological elastomer beam in buckling has been illustrated and compared in the case of compression and traction stresses found by Ritz approach and numerical methods, it is observed that the two curves are very close to each other for the two stresses, and the beam has an approximately stable 
behavior in the case of tensile stress, and an unstable behavior in the case of compressive stress.

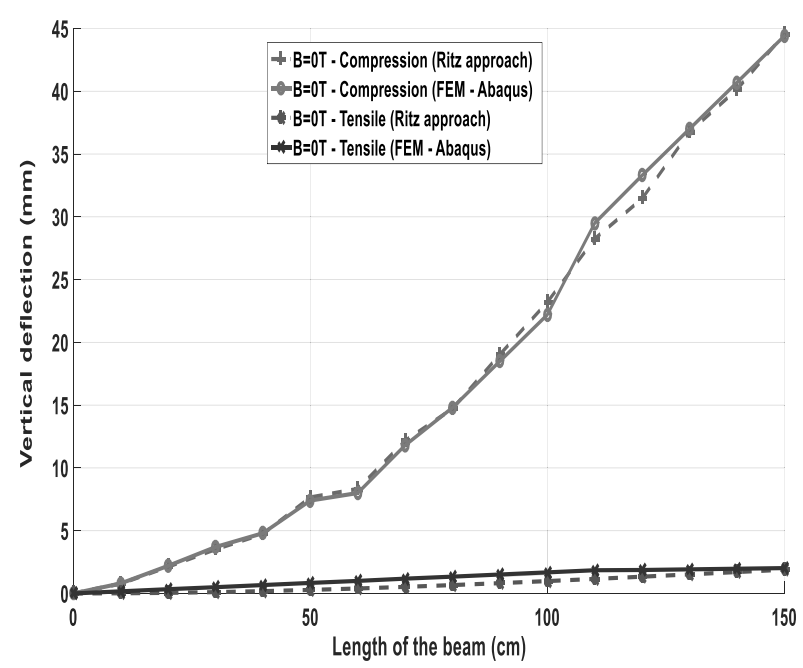

Fig. 10 Buckling deflection according to the length of the beam without magnetic field.
The same comparisons are made with the simulation of the behavior in compression of the beam (Figure 11); this figure shows a clear improvement on the instability of the behavior, the latter is adjusted by the application of a magnetic field. Indeed, the two curves are almost superimposed, which expresses a good modeling of the beam behavior, either by the Ritz approach or by numerical simulation. The most rigid structures in shear are the most exposed to the magnetic field. This allows us to conclude that the increase in the stiffness modulus of the elastomer material charged with iron particles produces an increase in the damping ratio. The improvement of the mechanical response by the application of a magnetic field on our structures is very significant compared to the response of other conventional structures. The figure also shows the advantage of the elaborated intelligent composite structures and that the buckling deflection is controlled by adjusting the rheological properties of the elastomer charged by the iron particles.

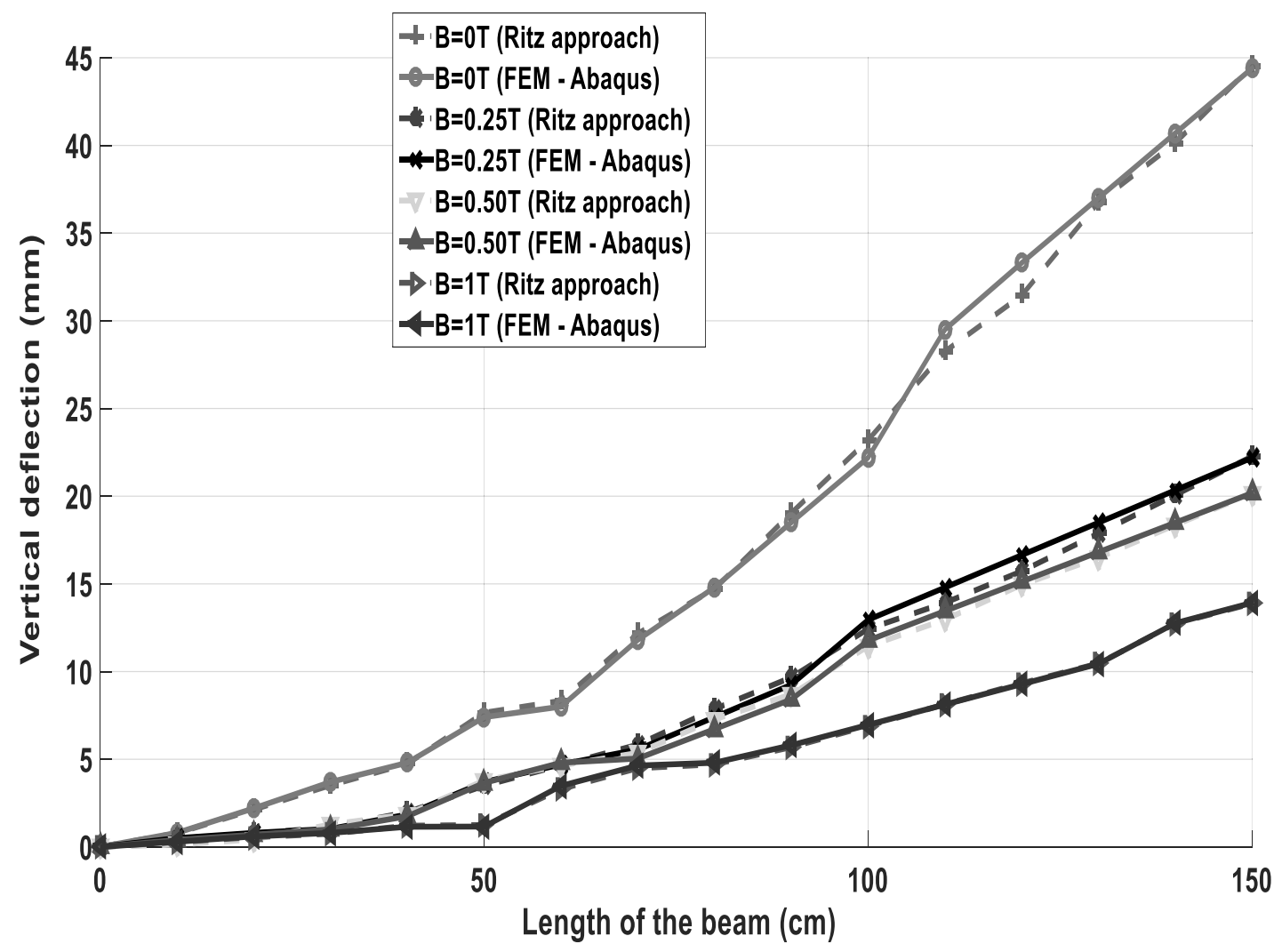

Fig. 11 Vertical deflection according to the length of the beam with applied magnetic field.

Table 3 represents the comparison of the vertical deflections obtained by the Ritz approach and numerical methods. These results are confronted with a lower average error of $5 \%$. It is also observed for the two methods that the deflection values decrease with the increase of the magnetic field intensity that is to say with the increase in the magnetic force Fm.

The results of the deflection as a function of the total load submitted by the magnetorheological elastomer beam, obtained from FEM simulations under the calculation code Abaqus corresponded well to the results obtained by the Ritz approach, these results are shown in Figure 12 and given in Table 4. It can be seen that the difference between the results obtained by the two methods does not exceed $9 \%$. 
Tab. 3 Comparison of the vertical deflections obtained by the Ritz approach and numerical methods

\begin{tabular}{|c|c|c|c|c|c|c|}
\hline & \multicolumn{3}{|c|}{$\mathrm{B}=0 \mathrm{~T}$} & \multicolumn{3}{|c|}{$\mathrm{B}=0.25 \mathrm{~T}$} \\
\hline $\mathrm{x}(\mathrm{cm})$ & $\begin{array}{l}\text { w Ritz approach } \\
(\mathrm{mm})\end{array}$ & $\begin{array}{l}\text { w numerical } \\
(\mathrm{mm})\end{array}$ & $\Delta \%$ & $\begin{array}{c}\text { w Ritz approach } \\
(\mathrm{mm})\end{array}$ & $\begin{array}{c}\mathrm{w} \text { numerical } \\
(\mathrm{mm})\end{array}$ & $\Delta \%$ \\
\hline 10 & 00.78 & 00.80 & 02.50 & 00.47 & 00.50 & 07.50 \\
\hline 20 & 02.13 & 02.20 & 03.29 & 00.76 & 00.80 & 05.26 \\
\hline 30 & 03.52 & 03.70 & 05.11 & 01.12 & 01.03 & 08.74 \\
\hline 40 & 04.74 & 04.80 & 01.26 & 01.98 & 01.85 & 07.03 \\
\hline 50 & 07.65 & 07.40 & 03.38 & 03.49 & 03.70 & 06.02 \\
\hline 60 & 08.33 & 08.00 & 04.12 & 04.66 & 04.70 & 00.08 \\
\hline 70 & 12.16 & 11.80 & 03.05 & 05.83 & 05.55 & 05.04 \\
\hline 80 & 14.72 & 14.80 & 00.54 & 07.86 & 07.40 & 06.22 \\
\hline 90 & 19.04 & 18.50 & 02.90 & 09.67 & 09.25 & 04.54 \\
\hline 100 & 23.20 & 22.20 & 04.50 & 12.43 & 12.95 & 04.18 \\
\hline 110 & 28.25 & 29.50 & 04.40 & 13.92 & 14.79 & 06.25 \\
\hline 120 & 31.45 & 33.30 & 05.88 & 15.72 & 16.64 & 05.84 \\
\hline 130 & 36.76 & 37.00 & 00.65 & 17.88 & 18.49 & 03.41 \\
\hline 140 & 40.14 & 40.70 & 00.65 & 20.07 & 20.34 & 01.34 \\
\hline \multirow[t]{2}{*}{150} & 44.55 & 44.39 & 00.34 & 22.27 & 22.19 & 00.36 \\
\hline & \multicolumn{3}{|c|}{$\mathrm{B}=0.5 \mathrm{~T}$} & \multicolumn{3}{|c|}{$\mathrm{B}=1 \mathrm{~T}$} \\
\hline $\mathrm{x}(\mathrm{cm})$ & $\begin{array}{c}\text { w Ritz approach } \\
(\mathrm{mm})\end{array}$ & $\begin{array}{c}\text { w numerical } \\
(\mathrm{mm})\end{array}$ & $\Delta \%$ & $\begin{array}{c}\text { w Ritz approach } \\
(\mathrm{mm})\end{array}$ & $\begin{array}{c}\mathrm{w} \text { numerical } \\
(\mathrm{mm})\end{array}$ & $\Delta^{\%} \%$ \\
\hline 10 & 00.13 & 00.14 & 07.69 & 00.28 & 00.30 & 07.14 \\
\hline 20 & 00.43 & 00.40 & 07.50 & 00.56 & 00.60 & 07.14 \\
\hline 30 & 01.28 & 01.40 & 09.37 & 00.75 & 00.80 & 06.66 \\
\hline 40 & 01.86 & 01.75 & 06.28 & 01.21 & 01.15 & 05.22 \\
\hline 50 & 03.79 & 03.65 & 03.83 & 01.25 & 01.16 & 07.76 \\
\hline 60 & 04.64 & 04.80 & 03.45 & 03.30 & 03.48 & 05.45 \\
\hline 70 & 05.36 & 05.04 & 06.35 & 04.49 & 04.64 & 03.34 \\
\hline 80 & 07.27 & 06.72 & 06.19 & 04.71 & 04.80 & 01.91 \\
\hline 90 & 08.70 & 08.41 & 03.45 & 05.69 & 05.80 & 01.93 \\
\hline 100 & 11.44 & 11.77 & 02.88 & 06.90 & 06.96 & 00.87 \\
\hline 110 & 12.96 & 13.45 & 03.78 & 08.13 & 08.12 & 00.12 \\
\hline 120 & 14.95 & 15.13 & 01.20 & 09.33 & 09.28 & 00.54 \\
\hline 130 & 16.49 & 16.81 & 01.94 & 10.46 & 10.44 & 00.19 \\
\hline 140 & 18.36 & 18.49 & 00.71 & 12.74 & 12.76 & 00.16 \\
\hline 150 & 20.15 & 20.18 & 00.15 & 13.88 & 13.92 & 00.29 \\
\hline
\end{tabular}

Tab. 4 Comparison of the buckling force-deflection curves obtained by the Ritz approach and numerical methods

\begin{tabular}{|c|c|c|c|c|c|c|}
\hline & \multicolumn{3}{|c|}{$\mathrm{B}=0 \mathrm{~T}$} & \multicolumn{3}{|c|}{$\mathrm{B}=0.25 \mathrm{~T}$} \\
\hline $\begin{array}{l}\mathrm{Nx} \\
(\mathrm{N})\end{array}$ & $\begin{array}{l}\text { w Ritz approach } \\
(\mathrm{mm})\end{array}$ & $\begin{array}{c}\text { w numerical } \\
(\mathrm{mm})\end{array}$ & $\Delta \%$ & $\begin{array}{l}\text { w Ritz approach } \\
(\mathrm{mm})\end{array}$ & $\begin{array}{c}\text { w numerical } \\
(\mathrm{mm})\end{array}$ & $\Delta \%$ \\
\hline 50 & 0.290 & 0.294 & 1.38 & 0.242 & 0.264 & 9.10 \\
\hline 100 & 0.578 & 0.602 & 4.15 & 0.498 & 0.542 & 8.83 \\
\hline 150 & 2.850 & 2.770 & 2.90 & 2.214 & 2.224 & 0.45 \\
\hline 200 & 7.600 & 7.542 & 0.77 & 4.542 & 4.563 & 046 \\
\hline 250 & 14.250 & 14.314 & 6.40 & 7.310 & 7.375 & 0.89 \\
\hline & \multicolumn{3}{|c|}{$\mathrm{B}=0.5 \mathrm{~T}$} & \multicolumn{3}{|c|}{$\mathrm{B}=1 \mathrm{~T}$} \\
\hline $\begin{array}{l}\mathrm{Nx} \\
(\mathrm{N})\end{array}$ & $\begin{array}{c}\text { w Ritz approach } \\
(\mathrm{mm})\end{array}$ & $\begin{array}{c}\text { w numerical } \\
(\mathrm{mm})\end{array}$ & $\Delta \%$ & $\begin{array}{c}\text { w Ritz approach } \\
(\mathrm{mm})\end{array}$ & $\begin{array}{c}\text { w numerical } \\
(\mathrm{mm})\end{array}$ & $\Delta \%$ \\
\hline 50 & 0.161 & 0.154 & 4.54 & 0.067 & 0.066 & 1.50 \\
\hline 100 & 0.385 & 0.389 & 1.04 & 0.168 & 0.159 & 5.66 \\
\hline 150 & 1.327 & 1.372 & 3.40 & 0.458 & 0.463 & 1.10 \\
\hline 200 & 3.220 & 3.290 & 2.17 & 1.241 & 1.231 & 0.80 \\
\hline 250 & 5.850 & 5.790 & 1.04 & 2.375 & 2.376 & 0.27 \\
\hline
\end{tabular}




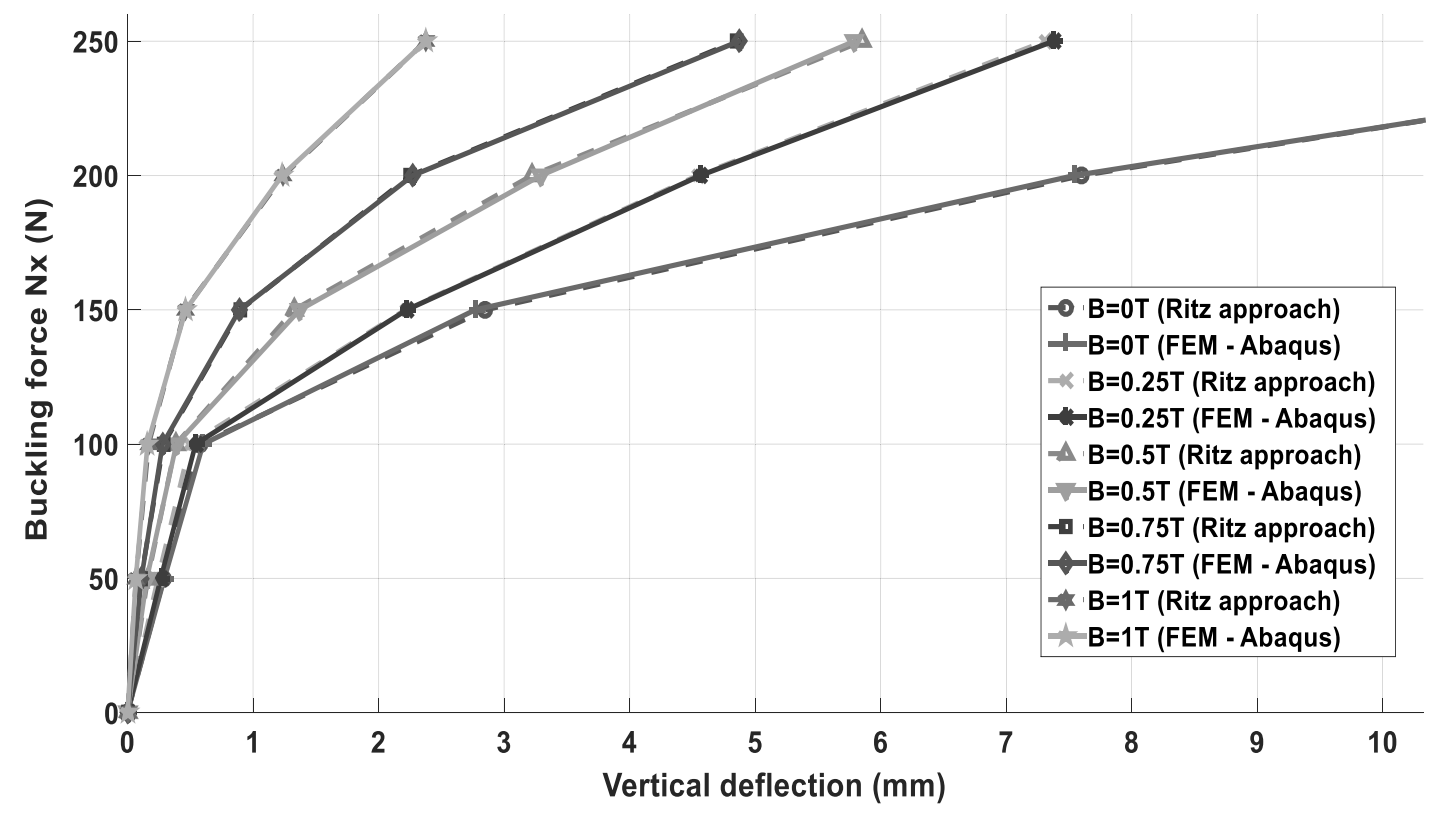

Fig. 12 Comparison of the buckling force-deflection curves.

\section{Conclusions}

This work concerns the Ritz approach and numerical study of a sandwich beam with a layer of magnetorheological elastomer.

The mechanical properties of the magnetorheological elastomer were determined experimentally by dynamic analysis and then used to simulate the buckling behavior of the beam, and the sandwich beam finite element model was derived using the Abaqus commercial finite element software and the brick element was used to mesh the entire system.

The function "fsolve" under Matlab was used to solve the approximation function.

The first results, presented in this article, showed that the magnetorheological elastomer layer can be used as an efficient solution to make structures subjected to buckling stress more stable due to the significant increase in the damping rate and the rigidity simultaneously by the use of a magnetic field.

The results obtained by numerical simulation and the Ritz approach model indicated that the structure proposed in this study could be used to reinforce the resistance of infrastructures to buckling.

In addition, the results found by the finite element model using Abaqus software, showed a satisfactory correlation with the results obtained by the Ritz approach model using Matlab code. Finally, this study shows a great interest in the remediation of the buckling effect in several fields of application (civil and mechanical engineering).

\section{Acknowledgment}

Thanks to Laboratory of Condensed Matter Physics (LPMC) University of Nice - Sophia Antipolis - France, for providing various supports for this study. We are also grateful to Messrs George Bossis Research Director Emeritus and Dr. Kuzhir Pavel of LPMC, for their help.

\section{References}

[1] SOOMIN, A., YOON, Y.K. (2021). Higher-order beam bending theory for static, free vibration, and buckling analysis of thin-walled rectangular hollow section beams. In: Computers Structures, Vol. 248, No., 106494.

[2] QIDUO, J., XUAN, H., YIRU, R., HONGYONG, J. (2020). On static and dynamic snap-throughs of the imperfect postbuckled FG-GRC sandwich beams. In: Journal of Sound and Vibration, Vol. 489, No., 115684.

[3] MASOUD, D., NIKNAM, M., THOMAS, A.B. (2021). Analytical and experimental study of a clamped-clamped, bistable buckled beam low-frequency PVDF vibration energy harvester. In: Journal of Sound and Vibration, Vol. 497, No., 115937.

[4] HANING, X., BENJAMIN, D.R. (2021). Modal analysis of post-buckled beams undergoing stable transitions between remote equilibria. In: Journal of Sound and Vibration, Vol. 501, No., 116039.

[5] NGOC, H.P., CAO, H.P., KIM, J.R.R. (2021). Global buckling capacity of cold-rolled aluminium alloy channel section beams. In: Journal of Constructional Steel Research, Vol. 179, No., 106521.

[6] XIAO-LEI, Y., GUO-QIANG, L., YANBOW, JIN, J. (2020). Experimental and numerical investigation on flexural-torsional buckling 
of Q460 steel beams. In: Journal of Constructional Steel Research, Vol. 174, No., 106276.

[7] CHENYU, L., JING, W., LUQI, X. (2021). Seismic performance of buckling-restrained reduced beam section connection for steel frames. In: Journal of Constructional Steel Research, Vol. 181, No., 106622.

[8] YUANBIN, W., WEIDONG, Z. (2021). Nonlinear transverse vibration of a hyperelastic beam under harmonic axial loading in the subcritical buckling regime. In: Applied Mathematical Modelling, Vol. 94, No., pp. 597-618.

[9] SAMIR, E., WALTER, L. (2021). Buckling and postbuckling of extensible, shear-deformable beams: Some exact solutions and new insights. In: International Journal of Non-Linear Mechanics, Vol. 129, No., 103667.

[10] JEN-SAN, C., LIEN-CHENG, W. (2020). Contact between two planar buckled beams pushed together transversely. In: International Journal of Solids and Structures, Vol. 199, No., pp.181-189.

[11] JIŘÍ M., IVO D. (2018). Properties of Electron Beam Hardened Layers made by Different Beam Deflection. In: Manufacturing Technology, Vol. 18, No. 2, pp. 279-284.

[12] ZONGXING, Z., SHANHUA, X., HAO, W., BIAO, N., CHAO, S. (2021). Flexural buckling behavior of corroded hot-rolled H-section steel beams. In: Engineering Structures, Vol. 229, No., 111614.

[13] ABO-BAKR, R.M., ABO-BAKR, H.M., MOHAMED, S.A., ELTAHER, M.A. (2021). Optimal weight for buckling of FG beam under variable axial load using Pareto optimality. In: Composite Structures, Vol. 258, No., 113193.

[14] CONG, I.L., NGOC, A.T.L., DINH, K.N. (2021). Free vibration and buckling of bidirectional functionally graded sandwich beams using an enriched third-order shear deformation beam element. In: Composite Structures, Vol.261, No., 113309.

[15] JUN, L., BING, H., WENBIN, Y., FAN, Y. (2021). High performance model for buckling of functionally graded sandwich beams using a new semi-analytical method. In: Composite Structures, Vol. 262, No., 113614.

[16] FARID, A., FADIA, A., CHAHMI, O. (2020). Buckling improvement of pretwisted universal steel beams. In: Thin-Walled Structures, Vol. 157, No., 107117.

[17] HADI, A., SEYYED, M.H.H., YASER, K.. (2021). Free vibration analysis of pre/post buckled rotating functionally graded beams subjected to uniform temperature rise. In: Thin-Walled Structures, Vol. 158, No., 107187.

[18] MOHAMMAD, A., FARSHID, N. (2021). Buckling and free vibration analyses of a sandwich beam made of a soft core with FG-GNPs reinforced composite face-sheets using Ritz Method. In: Thin-Walled Structures, Vol. 158, No., 107200.

[19] YOSHIHIRO, K., SZYMON, M.F., ATSUSHI, S. (2021). Elastic local buckling strength of I-beam cantilevers subjected to bending moment and shear force based on flange-web interaction. In: Thin-Walled Structures, Vol. 162, NO., 107633.

[20] LINH, T.M.P., TAN-TIEN, N., JAEHONG, L. (2021). Buckling analysis of open-section beams with thin-walled functionally graded materials along the contour direction. In: European Journal of Mechanics / A. Solids, Vol. 88, No., 104217.

[21] DITA, J. (2020). Comparison of Experimental Investigation of Deflection of the Sandwich Composite Beam by Optic-fibre Gauge with Theoretical Models. In: Manufacturing Technology, Vol. 20, No. 2, pp. 183-189.

[22] HANING, X., BENJAMIN, D.R. (2021). Stabilizing higher-order equilibria of post-buckled beams using piezoelectric actuation. In: European Journal of Mechanics / A Solids, Vol. 88, No., 104264.

[23] WENZHONG, Y., YUNCHEN, Y., ANKUR, M. (2019). Analytical modeling for rapid design of bistable buckled beams. In: Theoretical \& Applied Mechanics Letters, Vol. 9, No., pp. 264-272.

[24] FARZAD, E., PENDAR, H., ALI, D. (2021). Buckling analysis of embedded graphene oxide powder-reinforced nanocomposite shells. In: Defence Technology, Vol. 17, No., pp. 226-233.

[25] AGÜEROA, A., BALAZ, I., KOLEKOV, Y. (2021). New method for metal beams sensitive to lateral torsional buckling with an equivalent geometrical UGLI imperfection. In: Structures, Vol. 29, No., pp. 1445-1462.

[26] NEDJAR., A., AGUIB, S., DJEDID, T., NOUR, A., SETTET, A. T., TOURAB, M. (2019). Analysis of the Dynamic Behavior of Magnetorheological Elastomer Composite: Elaboration and Identification of Rheological Properties. In: Silicon, Vol. 11, pp.1287-1293.

[27] TOURAB., M, AGUIB., S. (2019). Experimental Analysis of The Thermal Effect of The Magneto- Mechanical Behavior of Viscoelastic Elastomer. I Adv Res Fluid Mech Thermal Sci., Vol. 53, pp.25-34. 